\title{
Comparação de Métodos de Avaliação de IHC sob a Perspectiva do Autor da Interface
}

\author{
Comparison of $\mathrm{HCl}$ Evaluation Methods from Interface Author's Perspective
}

\author{
SANTOS, Rafael Dias; Mestre; UFRN \\ rafaeldias.a@gmail.com \\ SILVA, Bruno Santana da; Doutor; UFRN \\ bruno@imd.ufrn.br
}

\section{Resumo}

Apesar de a academia recomendar a execução de métodos de avaliação de IHC por terceiros especialistas, algumas empresas não têm condições de segui-la. Como equipes pequenas conduzem avaliações com pouco conhecimento sobre IHC e design? É relevante o autor da interface avaliar sua própria solução de IHC? Este trabalho apresenta um estudo de caso que analisa a experiência de profissionais de TI em seus primeiros passos na condução de avaliações de IHC. Comparou-se a avaliação heurística, o método de avaliação de comunicabilidade e o teste de usabilidade sob a perspectiva do autor da interface, considerando tempo, materiais, pessoas envolvidas, resultados e dificuldades enfrentadas. Mesmo em condições não ideais, o autor da solução obteve resultados relevantes na avaliação formativa. Foram encontrados 27 problemas na avaliação heurística, 20 problemas no método de avaliação de comunicabilidade e 4 problemas no teste de usabilidade para orientar a melhoria da solução sendo concebida.

Palavras Chave: avaliação heurística; método de avaliação de comunicabilidade; teste de usabilidade; avaliação formativa.

\begin{abstract}
Although academy recommends execution of $\mathrm{HCl}$ evaluation methods by third party specialists, some companies are unable to follow them. How do small companies conduct evaluations with little knowledge about $\mathrm{HCl}$ and design? Is it relevant for the interface author to evaluate his own $\mathrm{HCl}$ solution? This work presents a case study that examines the experience of IT professionals conducting their first $\mathrm{HCl}$ evaluations. We compare heuristic evaluation, communicability evaluation method and usability test from interface author's perspective, considering involved time, materials and people, results and faced difficulties. Even on non-ideal conditions, the interface author found relevant results from formative evaluation. He found 27 problems in heuristic evaluation, 20 problems in communicability evaluation method and 4 problems in usability test to guide solution improvement.
\end{abstract}

Keywords: heuristic evaluation; communicability evaluation method; usability test; formative evaluation. 


\section{Introdução}

Avaliação é fundamental no processo de design (Lawson, 2006). Não importa quão cuidadosa tenha sido a concepção de um software, sempre é preciso verificar sua qualidade de uso. A literatura de Interação Humano-Computador (IHC) costuma recomendar a execução da avaliação por terceiros (não autores da solução) especialistas em IHC (Sharp et al., 2007).

Em equipes pequenas de desenvolvimento de software, geralmente os colaboradores se envolvem com muitas atividades do processo: análise, design, programação, testes/avaliação, etc. Por vezes, eles também acabam responsáveis pelo design da interface com usuário. Entretanto, muitos desses profissionais não são especialistas em IHC, nem possuem bons conhecimentos sobre métodos de avaliação da área. Como equipes pequenas conduzem avaliações com pouco conhecimento sobre IHC? É relevante o autor da interface avaliar sua própria solução de IHC? A execução da avaliação de IHC em contextos não ideais precisa ser mais bem compreendida.

A SoftUrbano é uma empresa de tecnologia da informação que oferece um sistema web para gestão de escritórios de advocacia. Depois de ter consolidado a versão web do sistema, ela decidiu desenvolver uma versão móvel para smartphone. Um dos 10 colaboradores da empresa foi o responsável por projetar a interface com usuário desta nova versão. Apesar de este colaborador ter concluído um curso superior em TI e não de Design, ele pode ser considerado como um designer neste caso em particular pela atividade que desempenhou. Antes de prosseguir com o desenvolvimento, o autor da interface começou a se questionar sobre a qualidade de uso da sua solução de IHC: Como avaliar a qualidade de uso? O próprio autor pode avaliar sua proposta de solução? Quais métodos seriam indicados? O que seria necessário para executá-los?

Este artigo apresenta um estudo de caso (Stake, 1995; Yin, 2011) que analisou a experiência de profissionais da SoftUrbano nas primeiras execuções de avaliação de IHC. Durante a avaliação formativa, os colaboradores da empresa executaram três métodos para identificar problemas na sua solução de IHC sendo concebida: avaliação heurística (Nielsen, 1994), método de avaliação de comunicabilidade (Prates et al., 2000) e teste de usabilidade (Rubin e Chisnell, 2008). O estudo de caso analisou a execução destes métodos considerando tempo, materiais, avaliadores e usuários necessários, resultados encontrados e dificuldades enfrentadas.

\section{Métodos de Avaliação de IHC}

A Avaliação Heurística $(\mathrm{AH})$ é um método de inspeção que orienta um grupo de avaliadores a navegarem pela interface em busca de potenciais problemas de usabilidade, com base num conjunto de heurísticas (Nielsen, 1994). Com uma lista de problemas encontrados individualmente, eles se reúnem para revisar os resultados individuais e gerar um relatório coletivo consolidado.

O Método de Avaliação de Comunicabilidade (MAC) observa experiências de uso do sistema para identificar problemas de comunicabilidade (Prates et al., 2000). Um dos seus diferenciais é ser fundamentado na teoria da engenharia semiótica (De Souza, 2005). Na preparação, o avaliador define tarefas a serem executadas por potenciais usuários e o perfil dos participantes; faz o recrutamento, prepara o material necessário e executa um teste-piloto. Para coletar dados, o avaliador observa cada participante executando as tarefas solicitadas em ambiente controlado, com gravação do vídeo de interação e aplica questionário pré e pós-teste. $\mathrm{Na}$ interpretação dos vídeos, o avaliador marca rupturas de comunicação usando etiquetas com 
expressões comuns dos usuários. Os resultados são consolidados com a análise de todas as rupturas de comunicação identificadas e a elaboração de um perfil semiótico.

O Teste de Usabilidade (TU) é um método de observação que busca identificar problemas de usabilidade durante a execução de determinadas tarefas por potenciais usuários (Rubin e Chisnell, 2008). O TU não se distingue de forma significativa do MAC até a preparação e coleta de dados. As distinções se evidenciam nas próximas atividades. Para interpretar os dados e consolidar os resultados, o avaliador realiza medições e sumariza os resultados encontrados. Esta costuma ser apenas uma análise quantitativa, apesar de alguns autores defenderem também uma análise qualitativa no TU.

\section{Estudo de caso}

O objetivo desta pesquisa foi investigar o emprego de $\mathrm{AH}, \mathrm{MAC}$ e TU pelo próprio autor conduzindo uma avaliação formativa para identificar problemas na sua proposta de interface. Para tanto, considerou-se as seguintes perguntas: Quais atividades foram realizadas? Quanto tempo foi necessário? Quais materiais foram utilizados? Qual a infraestrutura necessária? Quantos avaliadores? Qual o perfil necessário? Quantos usuários? Qual o perfil desejado? Quais foram os resultados? Quais dificuldades os avaliadores enfrentaram na execução dos métodos?

\subsection{Metodologia}

Esta pesquisa exploratória (Marconi e Lakatos, 2010) realizou um estudo de caso (Stake, 1995; Yin, 2011) da experiência de profissionais durante uma avaliação formativa de IHC (Barbosa e Silva, 2010). As intervenções que esta pesquisa fez na prática profissional foram apenas (1) definição da ordem de execução dos métodos e (2) requerer um registro cuidadoso das atividades executadas.

Primeiro foi executada a $\mathrm{AH}$ para que a inspeção não sofresse influência dos problemas vivenciados pelos usuários nos métodos de observação. Depois, como a preparação e a coleta de dados do MAC e TU são equivalentes, o avaliador conduziu um único conjunto de observações de uso para os dois métodos. O avaliador analisou essas observações primeiro de acordo com o MAC, e depois de acordo com o TU. A ordem de execução do MAC e TU não deve ter influenciado significativamente as avaliações porque os métodos analisam critérios de qualidade diferentes, com dados de tipos distintos. O MAC avalia a comunicabilidade com base em dados qualitativos e o TU analisa a usabilidade com dados quantitativos, prioritariamente.

O avaliador registou dados com anotações pessoais e em artefatos produzidos de acordo com os próprios métodos. Ao terminar a execução de cada método, o avaliador respondeu às perguntas de investigação descritas acima com base na experiência que acabou de ter. Por fim, essas respostas foram comparadas e discutidas.

Todos os métodos foram executados com um protótipo executável num smartphone (Santos, 2016). Este protótipo recebeu dados reais atualizados para oferecer uma experiência próxima do produto final. Toda a interface do aplicativo fez parte do escopo das 3 avaliações.

\subsection{Execução da Avaliação Heurística}

\subsubsection{Perfil dos Avaliadores}

A $\mathrm{AH}$ foi realizada por 3 colaboradores da empresa. O Avaliador 1 (A1) é engenheiro da computação. Desenvolve a versão web do sistema e conhece bem suas funcionalidades. Não 
possui experiência em IHC e teve primeiro contato com a área neste estudo. O Avaliador 2 (A2) é engenheiro da computação. Participou do projeto do sistema web. Teve contato inicial com IHC em disciplina, mas não possui experiência profissional relevante na área. O Avaliador 3 (A3) cursou Analise e Desenvolvimento de Sistemas. Foi desenvolvedor da versão web do sistema. Apesar de ter tido experiências acadêmicas na área de IHC, ainda não desenvolveu atividades profissionais relevantes na área. Neste estudo, A3 realizou o projeto da interface avaliada, com alguma colaboração do A2 (discussão de ideias iniciais). O A1 não se envolveu no projeto da interface avaliada.

\subsubsection{Resultados da Análise da Execução da AH}

Os avaliadores já conheciam os usuários e o domínio, então não foi necessária nenhuma investigação específica. Como eles não conheciam o método ou haviam estudado há algum tempo, todos leram previamente a descrição em (Barbosa e Silva, 2010).

Os avaliadores seguiram a estratégia de verificar tela por tela se alguma heurística foi violada. Cada avaliador anotou os problemas encontrados com: descrição do problema, heurística violada, local de ocorrência e gravidade. Depois, os avaliadores se reuniram para discussão de cada problema. Foi gerado um relatório consolidado. No final da reunião de consolidação, cada avaliador respondeu a pergunta "Que dificuldades você encontrou na execução da AH?".

A análise dos dados coletados respondeu as questões de investigação, conforme descrito a seguir.

Quais atividades foram realizadas? Quanto tempo foi necessário? A3 levou 1h40min para preparar sozinho o material: preparação de dados reais e instalação do protótipo no smartphone e elaboração do modelo de documento para anotações dos avaliadores. A leitura da descrição do método não foi considerada no tempo de execução da $A H$. A1 levou 53min, A2 levou 1 h20min e A3 levou 30min para concluir a inspeção individual. Assim, coleta e interpretação dos dados consumiram um total de $2 \mathrm{~h} 43 \mathrm{~min}$. Por fim, a reunião de consolidação durou $40 \mathrm{~min}$. No total, a AH durou 5 h3min.

Essa análise deve considerar o envolvimento do avaliador no projeto de interface do protótipo avaliado. A3 fez a inspeção significativamente mais rápida, provavelmente porque foi autor principal do projeto de interface. Por outro lado, ter uma noção geral do projeto de interface não parece ter influenciado significativamente o tempo de execução da inspeção dos demais avaliadores. A1 fez uma inspeção mais rápida do que $A 2$, mas apenas o segundo participou de discussões iniciais do projeto de interface sendo avaliado.

Quais materiais foram utilizados? Qual a infraestrutura necessária? Numa sala de reunião, eles usaram um smartphone com o protótipo e um computador.

Quantos usuários? Qual o perfil desejado? Nenhum usuário se fez necessário.

Quantos avaliadores? Qual o perfil necessário? Três avaliadores participaram da avaliação. Apesar de A1 e A2 não conhecerem AH, a explicação em (Barbosa e Silva, 2010) foi suficiente. $A 3$ já havia realizado duas $A H s$ em experiências acadêmicas. Eles não demonstraram dificuldades em identificar problemas, se colocando facilmente no lugar de usuários.

Quais foram os resultados? Foram encontrados um total de 27 problemas de usabilidade, conforme descrito em (Santos, 2016). Individualmente, A1 encontrou 13 problemas, A2 encontrou 
18 problemas e A3 (o autor da interface) encontrou 7. Os 27 problemas encontrados violaram a maioria das heurísticas, exceto a de "Prevenção de erros" e "Ajude os usuários a reconhecer, diagnosticar e corrigir erros". A maior quantidade de problemas identificados violaram as heurísticas de "Flexibilidade e eficiência do uso" e "Controle e liberdade do usuário". A distribuição da severidade foi de $55 \%$ de problemas cosméticos, $22 \%$ pequenos, $11 \%$ grandes e mais $11 \%$ catastróficos.

Que dificuldades os avaliadores enfrentaram na execução da AH? A3 não apresentou dificuldade em preparar a AH. A inspeção foi influenciada pelo envolvimento dos avaliadores no projeto. Aqueles que não participaram do projeto de interface ou participaram de poucas discussões iniciais (A1 e A2), conseguiram identificar uma boa quantidade de problemas sem dificuldades. Entretanto, o autor da interface (A3) relatou "A maior dificuldade foi realizar a avaliação de uma coisa que eu mesmo projetei e sabia onde cada coisa estava. Talvez por isso não tenha encontrado muitos problemas". Ele identificou uma média de menos 8 problemas $(-50 \%)$ do que os demais avaliadores. Entretanto, A3 encontrou 3 problemas ( 1 cosmético e 2 catastróficos) que os outros não identificaram. Isso torna relevante sua participação na $\mathrm{AH}$, além da sua atuação como estimulador e guia dos demais avaliadores.

Todos demonstraram alguma dificuldade para interpretar os problemas identificados. A1 e A3 relaram dificuldades para identificar qual heurística foi violada. Para os avaliadores, suas dúvidas na identificação da heurística violada foram resolvidas com uma releitura da definição. Apenas o A2 relatou dificuldade em definir a gravidade dos problemas encontrados, principalmente na diferenciação entre problemas cosméticos e pequenos; ou seja, na definição de qual problema deveria ser resolvido ou poderia permanecer assim até segunda ordem. Todos foram capazes de sugerir soluções para os problemas encontrados.

$\mathrm{O}$ relato dos resultados desta $\mathrm{AH}$ teve características peculiares por ter sido feita pelo autor da interface com a participação e para a própria equipe de desenvolvimento. As descrições dos problemas foram muito resumidas, a ponto de quem não participou da avaliação ter dificuldades de compreendê-los lendo o texto. O relato não apresentou ilustrações, justificativas e nem indicação precisa do local da interface em que os problemas ocorreram. Seria uma documentação ruim caso fosse destinada a outras pessoas. Porém, na perspectiva prática de uma equipe que trabalha com desenvolvimento ágil, o relatório de avaliação apresentado parece ser uma documentação suficiente para consumo imediato da própria equipe.

\subsection{Execução do Método de Avaliação de Comunicabilidade}

A preparação e a coleta de dados foram as mesmas para o MAC e o TU. Eles diferenciaramse na interpretação e consolidação dos resultados. Houve uma preocupação ética com o envolvimento de pessoas na avaliação, em particular para garantir privacidade e anonimato.

O questionário pré-teste investigou a formação e atuação profissional dos participantes, sua experiência com sistemas semelhantes, bem como sobre o uso de smartphone. O questionário pós-testes investigou a opinião dos participantes sobre a experiência de uso observada.

Não foi necessária uma inspeção prévia da interface, pois o avaliador foi autor da interface. As treze tarefas propostas aos participantes cobriram todos os principais conceitos do aplicativo móvel: usuários, processos, arquivos, eventos e contatos. As tarefas estão descritas detalhadamente em (Santos, 2016). Elas foram revisadas por um advogado para verificar sua 
compreensão e pertinência prática.

Os materiais utilizados na coleta foram um smartphone Android com tela de 5.1" e uma filmadora profissional com tripé. No smartphone, um gravador de áudio nativo registrou as entrevistas pré e pós-teste, e o gravador de tela AZ Screen Recorder registrou vídeos com o que apareceu na tela durante a interação, junto com o áudio do microfone. Por segurança, uma filmadora profissional gravou as mãos dos participantes usando o dispositivo.

Um colaborador da empresa participou do teste piloto. $O$ avaliador percebeu a necessidade de atualizar o protótipo com dados das tarefas e de definir um roteiro para observação. Os materiais necessários foram revisados.

O avaliador realizou 3 visitas ao Núcleo de Prática Jurídica (NPJ) da UFRN para recrutar os participantes. Numa sala de reunião do NPJ, o avaliador posicionou mesa, cadeira e filmadora para gravar as mãos do participante. Ao receber cada participante, o avaliador explicou os objetivos da avaliação e os cuidados éticos tomados. $O$ participante assinou o termo de consentimento. $O$ avaliador leu, então, o questionário pré-teste para que o participante respondesse oralmente. 0 avaliador continuou lendo uma tarefa por vez para que o participante pudesse utilizar o protótipo, obter e dizer o resultado solicitado. A leitura das tarefas foi uma tentativa de tornar mais rápida a observação, porém os participantes não esperavam o avaliador concluir a leitura e já tentavam executar a tarefa. Por isso ocorreram alguns equívocos decorrentes da interpretação errônea da tarefa. No final, o participante respondeu oralmente um questionário pós-teste.

A preparação levou 5h54min: recrutamento dos participantes (1h30min), preparação do material (3h30min), revisão das tarefas com advogado (60min), execução do teste piloto (44min), impressão e arrumação do material para levar para sala de observação (15min), preparação da filmadora (15min) e do ambiente (10min). A coleta de dados de todos os participantes durou 1h23min. Em média cada participante levou 16min36s na sessão de observação.

\subsubsection{Perfil dos Participantes}

Os cinco participantes trabalhavam no NPJ da UFRN. Dois são experientes advogados e professores de Direito, formados há mais de dez anos. Os outros três participantes eram estudantes graduação de cursos diferentes de Direito. Seus conhecimentos sobre Direito decorrem de suas atividades no NPJ há pelo menos 6 meses. Todos possuem smartphone e fazem uso de diversos aplicativos.

\subsubsection{Perfil do Avaliador}

$\mathrm{O}$ avaliador do MAC e TU foi o autor da interface avaliada, ou seja, o A3 da AH.

\subsubsection{Resultados da Análise da Execução do MAC}

O avaliador etiquetou os vídeos de interação gravados pelo smartphone. Ele realizou uma análise intrassujeito dos vídeos, participante por participante. As rupturas de comunicação encontradas foram anotadas com: tarefa, período em que ocorreu, sintoma, etiqueta e eventuais observações. Ele não sentiu necessidade de analisar os vídeos gravados pela filmadora mostrando as mãos do usuário. Depois da etiquetagem, o avaliador ouviu os áudios dos questionários préteste para escrever o perfil dos participantes. Com o perfil escrito, o avaliador releu sua etiquetagem dos vídeos para relacionar o comportamento do participante com seu perfil. Nesta releitura, ele atualizou observações e começou a pensar em propostas de soluções. 
$\mathrm{Na}$ consolidação, o avaliador realizou a análise interssujeito tabulando os resultados da etiquetagem por tarefa e por participante. A interpretação da tabulação por tarefa permitiu que o avaliador tivesse uma visão geral das rupturas de comunicação que ocorreram numa parte da interface. Analisando os sintomas das rupturas e perfil dos participantes, o avaliador conseguiu identificar prováveis causas para as rupturas observadas, ou seja, problemas na solução avaliada. Desse modo, o avaliador pode indicar uma possível solução para os problemas encontrados.

O questionário pós-teste não contribuiu para a interpretação dos resultados, pois os participantes não conseguiram perceber, nem refletir sobre, as dificuldades vivenciadas. Eles concentraram-se em sugerir novas funcionalidades. Depois do relato dos resultados, o avaliador respondeu "Que dificuldades encontrou na execução do MAC?".

A análise desta execução do MAC respondeu as questões de investigação, conforme descrito a seguir.

Quais atividades foram realizadas? Quanto tempo foi necessário? A preparação levou $5 \mathrm{~h} 54 \mathrm{~min}$ e a observação durou $1 \mathrm{~h} 23 \mathrm{~min}$. Os vídeos foram etiquetados em $3 \mathrm{~h}$. A análise das rupturas de comunicação durou $4 \mathrm{~h}$, enquanto que a identificação dos problemas causadores dessas rupturas e as propostas de correções duraram 4h30min. No total, MAC durou 17h24min.

Quais materiais foram utilizados? Qual a infraestrutura necessária? Os materiais utilizados foram: documentos impressos, filmadora, tripé e smartphone com o protótipo e gravador de áudio e vídeo. Também foi utilizado um computador com editor de textos e reprodutor de áudios e vídeos. Os dados coletados pela filmadora não foram relevantes. As observações ocorreram numa sala de reunião.

Quantos usuários? Qual o perfil desejado? Foram seis participantes, sendo um para o teste piloto e cinco para a coleta principal. Os participantes deveriam ter boas noções de Direito. Entretanto, apenas dois participantes atenderam essa expectativa por serem advogados. Os outros três tinham poucas noções pela experiência de trabalho no NPJ e eram alunos de outros cursos superiores da universidade.

Quantos avaliadores? Qual o perfil necessário? Somente uma pessoa conduziu o MAC. Ele não conhecia o método e considerou suficiente ler a explicação de (Barbosa e Silva, 2010) para executá-lo. Quando foi relatar seus resultados, ele sentiu necessidade de analisar um exemplo de documentação.

Quais foram os resultados? Foram identificados 20 problemas (características da interface), que podem ter gerado as 41 rupturas de comunicação durante a observação de uso dos cinco participantes. Cada problema recebeu sugestão de solução (melhoria na interface). A diferença do total de etiquetas entre os advogados (média de 8,5 ) e os bolsistas (média de 7,6 ) foi pequena. A Tarefa 1 (inscrição de um novo usuário) concentrou a maior ocorrência de rupturas de comunicação (30\%). Isso requer atenção, pois existe a expectativa dela ser a porta de entrada para futuros clientes. Por outro lado, a Tarefa 10 (encontrar o nome do advogado citado num arquivo) não apresentou rupturas. No restante das tarefas, houve uma boa distribuição das etiquetas.

Que dificuldades o avaliador enfrentou na execução do MAC? As três visitas ao NPJ para recrutamento exigiram tempo e deslocamento significativos. Infelizmente não foi possível contar com a participação de alunos de Direito. Os participantes que não cursaram Direito tiveram dificuldades em executar algumas tarefas que exigiam mais conhecimentos sobre a Justiça 
brasileira. Foi possível e necessário distinguir os problemas decorrentes da falta de conhecimento do domínio. Porém, tal distinção provavelmente exigiu tempo e esforço extra do avaliador.

A coleta de dados foi prejudicada por utilizar apenas comunicação oral entre avaliador e participante. Além de o participante cometer equívocos por não esperar a conclusão da leitura da tarefa antes de começar a interagir, o avaliador gastou certo tempo para identificar as respostas de cada tarefa nas falas dos participantes.

A maior dificuldade na interpretação foi determinar a etiqueta que corresponde à ruptura de comunicação observada. Existem etiquetas parecidas que se diferenciam por pequenos detalhes. Isso requer bastante atenção e uma melhor compreensão do que está sendo observado.

$\mathrm{Na}$ consolidação e relato dos resultados, o avaliador optou por não elaborar o perfil semiótico previsto pelo método, pois o considerou muito teórico, complexo e não conseguiu identificar sua utilidade prática. Como alternativa, ele preferiu identificar os problemas que teriam gerado as rupturas de comunicação identificadas, e sugerir soluções que serão consideradas no seu projeto de IHC.

\subsection{Execução do Teste de Usabilidade}

O TU realizado identificou problemas de eficiência de uso e facilidade de aprendizado do protótipo. A preparação e a coleta de dados foram as mesmas do MAC. O TU diferenciou-se a partir da interpretação. $O$ avaliador assistiu a cada vídeo de interação anotando: o tempo inicial em que leu a tarefa (início da tarefa), os desvios dos caminhos produtivos, os pedidos de ajuda, os resultados da tarefa e o tempo em que o usuário acabou de dizê-los (fim da tarefa). Semelhante ao MAC, o avaliador também não sentiu necessidade de assistir os vídeos gravados pela filmadora.

Na consolidação, o avaliador realizou uma análise intersujeito quantitativa. Ele contabilizou suas medições por participante e por tarefas. A partir dos sintomas observados, o avaliador buscou identificar os problemas e propor soluções. Como no MAC, o questionário pós-teste também não contribuiu para a interpretação dos resultados. No relato dos resultados, o avaliador apresentou uma lista de problemas encontrados. Depois de concluir o TU, ele respondeu "Que dificuldades encontrou na execução do TU?".

A análise desta execução do TU respondeu as questões de investigação, conforme descrito a seguir.

Quais atividades foram realizadas? Quanto tempo foi necessário? O planejamento (5h54min) e a coleta de dados (1h23min) foram reaproveitados do MAC. A interpretação, consolidação e relato dos resultados levaram 14h4min envolvendo: definição das perguntas e roteiro para a análise dos vídeos, definição do caminho produtivo previsto para cada tarefa, análise dos vídeos, contabilização dos resultados e identificação dos problemas e sugestão de solução. No total, o TU durou 21h21min.

Quais materiais foram utilizados? Qual a infraestrutura necessária? Os mesmos do MAC.

Quantos usuários? Qual o perfil desejado? Os mesmos do MAC. A falta de conhecimento do domínio de alguns participantes impediu que alguns concluíssem determinadas tarefas e/ou pedissem ajuda ao avaliador.

Quantos avaliadores? Qual o perfil necessário? O mesmo que conduziu o MAC. Ele não conhecia o TU e achou suficiente ler a explicação de (Barbosa e Silva, 2010) para executá-lo. 
Quais foram os resultados? Foram encontrados 5 problemas (características indesejáveis) com o TU; sendo 3 problemas na interface, que provavelmente causaram comportamentos indesejáveis relacionados a facilidade de aprendizado (2) e a eficiência (1); outro problema na implementação (bug) e mais um problema sobre a falta de conhecimento de domínio. Os insucessos na conclusão das tarefas permitiram classificar um problema como falta de conhecimento de domínio, pois os participantes explicitamente diziam não saber do que se tratava a tarefa ou respondiam algo sem relação conceitual com a tarefa.

Os participantes cometeram o maior número de erros na Tarefa $9^{1}$. Quase todos participantes, exceto $\mathrm{P} 2$, tiveram dificuldades nela. Os participantes também apresentaram número de erros relevante nas Tarefas 2,4 e 8 . Pelo menos um participante cometeu um erro nas demais tarefas.

Os participantes conseguiram concluir pelo menos 10 tarefas com sucesso $(76 \%$ de aproveitamento). Apenas o Participante 2 conseguiu concluir todas as 13 tarefas com sucesso. As Tarefas 1, 4, 5, 7, 8, 10, 11 e 12 foram concluídas com sucesso por todos os participantes. As Tarefas 6 e 9 não foram concluídas por um participante (P5 e P4, respectivamente). As Tarefas 2, 3 e 11 não foram concluídas por dois participantes. É interessante observar que os advogados conseguiram concluir quase todas as tarefas, enquanto os outros tiveram maior dificuldade.

Apenas os Participantes 1 e 4 pediram ajuda uma única vez durante as Tarefas 1 e 5, respectivamente. É importante observar que um deles é advogado e o outro não.

A eficiência foi verificada pela definição de um tempo aceitável para execução de cada tarefa. O tempo aceitável foi $30 \%$ maior do que a média do tempo de execução dos participantes que seguiram o caminho previsto pelo autor da interface e concluíram a tarefa com sucesso, sem solicitação de ajuda. Quando o tempo de execução foi maior do que o respectivo tempo aceitável, ele foi considerado ineficiente. Todas as execuções da Tarefa 1 foram eficientes. Tarefa 11 teve uma execução ineficiente. As demais tarefas tiveram mais de uma execução ineficiente. Novamente, a Tarefa 9 foi a mais problemática, com quase todos participantes com tempos ineficientes. Todos participantes tiveram pelo menos uma execução ineficiente. Considerando todas as tarefas, três participantes ficaram abaixo ou muito próximos do tempo total aceitável. Apenas um advogado e um bolsista gastaram mais de dois minutos além do aceitável.

Que dificuldades enfrentou na execução do TU? Como preparação e coleta de dados do TU foram as mesmas do MAC, as distinções surgiram principalmente na interpretação dos dados. $\mathrm{O}$ avaliador não teve dificuldade em realizar uma análise quantitativa dos vídeos com as medições indicadas pelo TU: desvios cometidos, pedidos de ajuda, conclusões bem-sucedidas e tempos de execução. Contudo, o TU quase não ofereceu apoio para realizar uma análise qualitativa identificando a causa das medidas obtidas. $O$ avaliador teve dificuldade de explicar porque um erro foi cometido ou porque um participante demorou para concluir determinada tarefa, por exemplo. Como consequência, o avaliador não foi capaz de identificar boa parte dos problemas na interface que teriam levado às medidas indesejadas. A execução do TU possibilitou ao autor perceber que sua proposta de interface está ruim, mas pouco contribuiu para seu reprojeto.

\footnotetext{
${ }^{1}$ As tarefas estão descritas detalhadamente em (Santos, 2016)
} 


\section{Comparação da Execução dos Métodos de Avaliação}

A AH teve um esforço menor de preparação, pois não envolveu a participação de usuários. $\mathrm{Na} \mathrm{AH}$, os avaliadores coletaram e interpretaram dados concomitantemente. Já no MAC e TU, primeiro o avaliador coletou os dados, para somente depois interpretá-los. As diferenças ficam mais evidentes quando comparamos a quantidade de horas trabalhadas em cada método (Tabela 1). A AH exigiu $5 \mathrm{~h} 03 \mathrm{~min}$ de trabalho, o MAC consumiu $17 \mathrm{~h} 24 \mathrm{~min}(+244 \%$ da $\mathrm{AH}$ ) e o TU, $21 \mathrm{~h} 21 \mathrm{~min}$ (+322\% da $\mathrm{AH},+22 \%$ do $\mathrm{MAC})$.

Tabela 1 - Comparação do tempo de execução dos métodos.

\begin{tabular}{|c|c|c|c|}
\hline atividade & $\mathbf{A H}$ & MAC & TU \\
\hline preparação & 1h40min & 5 h54min & $5 \mathrm{~h} 54 \mathrm{~min}$ \\
\hline coleta de dados & \multirow[t]{2}{*}{$\begin{array}{l}\text { A1: } 53 \mathrm{~min} \\
\text { A2: } 1 \mathrm{~h} 20 \mathrm{~min} \\
\text { A3: } 30 \mathrm{~min} \\
\text { média: } 54 \mathrm{~min} \\
\text { subtotal: } 2 \mathrm{~h} 43 \mathrm{~min}\end{array}$} & $\begin{array}{l}\text { P1: } 17 \mathrm{~min} \\
\text { P2: } 17 \mathrm{~min} \\
\text { P3: } 15 \mathrm{~min} \\
\text { P4: } 17 \mathrm{~min} \\
\text { P5: } 17 \mathrm{~min} \\
\text { média: } 16 \mathrm{~min} 36 \mathrm{~s} \\
\text { subtotal: } 1 \mathrm{~h} 23 \mathrm{~min}\end{array}$ & $\begin{array}{l}\text { P1: } 17 \mathrm{~min} \\
\text { P2: } 17 \mathrm{~min} \\
\text { P3: } 15 \mathrm{~min} \\
\text { P4: } 17 \mathrm{~min} \\
\text { P5: } 17 \mathrm{~min} \\
\text { média: } 16 \mathrm{~min} 36 \mathrm{~s} \\
\text { subtotal: } 1 \mathrm{~h} 23 \mathrm{~min}\end{array}$ \\
\hline interpretação & & $3 \mathrm{~h}$ & \multirow[t]{3}{*}{ 14h04min } \\
\hline consolidação & \multirow{2}{*}{$40 \mathrm{~min}$} & \multirow{2}{*}{ 8h30min } & \\
\hline relato dos resultados & & & \\
\hline total & 5 h03min & $17 \mathrm{~h} 24 \mathrm{~min}$ & $21 \mathrm{~h} 21 \mathrm{~min}$ \\
\hline
\end{tabular}

Os métodos de observação demandaram mais de $12 \mathrm{~h}$ além do método de inspeção, considerando um tempo de observação médio de $16 \mathrm{~min} 36 \mathrm{~s}$ para 5 participantes. Se número de participantes fosse maior ou as tarefas demorassem mais, provavelmente essa diferença entre os métodos de inspeção e de observação seria ainda maior. O TU precisou de mais $4 \mathrm{~h}$ comparado ao MAC, porque a análise dos desvios dos caminhos produtivos no TU demorou mais do que a etiquetagem dos vídeos no MAC, segundo o avaliador. No primeiro caso, cada passo diferente foi relevante, pois foi contabilizado como um erro. No segundo, o foco era analisar uma ruptura de comunicação envolvendo um conjunto de passos de interação. Boa parte das vezes a identificação de rupturas de comunicação não necessita da comparação dos passos observados com um caminho produtivo e, quando precisa, trata-se apenas da verificação de que o caminho observado é ou não produtivo, independente de desvios individuais de cada passo de interação. Essa diferença entre MAC e TU contraria a expectativa de que uma análise quantitativa seja mais rápida do que uma análise qualitativa. Nem sempre é o caso, em particular quando o cálculo for manual.

Quais materiais foram utilizados? Qual a infraestrutura necessária? Os materiais utilizados foram quase os mesmos em todos os métodos: smartphone com protótipo, computador com editor de textos e documentos impressos. Os métodos de observação também utilizaram programas de gravação de áudio e vídeo da tela no smartphone, e uma filmadora cujos vídeos acabaram não sendo utilizados durante a análise dos dados. Todos os métodos usaram uma sala de reunião, seja para a inspeção ou para a observação.

Quantos avaliadores? Qual o perfil necessário? A AH exigiu mais avaliadores do que os métodos de observação. Na opinião dos avaliadores foi suficiente ler uma descrição dos métodos para ser capaz de executá-los. No relato dos resultados do MAC, o avaliador também sentiu necessidade de consultar um exemplo de relato. A falta de conhecimento e prática de IHC não foi impeditiva para execução dos 3 métodos. Entretanto, os resultados das avaliações não foram 
verificados para identificação de falsos positivos e falsos negativos. Esta verificação está fora do escopo deste artigo.

Quantos usuários? Qual o perfil desejado? Apenas o MAC e o TU envolveram a participação de usuários. Foram 6 participantes, um para o estudo piloto e os demais para a observação de uso. O recrutamento exigiu esforço e tempo consideráveis. O perfil dos participantes foi um fator importante. Os que tinham pouco conhecimento sobre a área jurídica vivenciaram problemas em tarefas conceitualmente mais complexas.

Quais foram os resultados? Comparou-se quantidade, gravidade e sobreposição dos problemas encontrados por AH, MAC e TU. A AH encontrou 27 problemas, o MAC identificou 20 problemas e o TU apontou 5 problemas. As gravidades dos problemas foram mapeadas neste trabalho para a escala de problema pequeno, médio e grande, conforme a Tabela 2. A Tabela 3 apresenta a quantidade de problemas por gravidade em cada método. A AH encontrou o maior número de problemas pequenos. Não houve diferença significativa na quantidade de problemas médios e graves entre AH e MAC. O TU resultou em poucos problemas porque o avaliador teve dificuldade de identificá-los (causas) a partir dos sintomas contabilizados. A Tabela 3 também apresenta a quantidade de problemas únicos, identificados apenas por um dos métodos, e sobrepostos, identificados por mais de um método. Todos os métodos encontraram problemas únicos, com destaque para $\mathrm{AH}$, e também sobrepostos, com destaque para o MAC. Isso pode ter ocorrido porque na $\mathrm{AH}$ os avaliadores realizaram uma exploração livre na interface, enquanto que no MAC os participantes são guiados por um conjunto específico de tarefas que limitam o escopo de análise. Não é possível afirmar que um método de inspeção substitui um método de observação, nem vice-versa, pois temos considerável número de problemas em locais únicos em ambos. Deste modo, um método de observação pode identificar um conjunto de problemas complementar a um método de inspeção.

Tabela 2 - Comparação da gravidade nos três métodos.

\begin{tabular}{|l|l|l|l|}
\hline classificação & AH & MAC & TU \\
\hline problema grande & problema catastrófico & falha de comunicação completa & insucesso \\
\hline problema médio & problema grande & $\begin{array}{l}\text { falha de comunicação } \\
\text { temporária }\end{array}$ & $\begin{array}{l}\text { pedido de ajuda ou tempo } \\
\text { de execução ineficiente }\end{array}$ \\
\hline problema pequeno & $\begin{array}{l}\text { problema pequeno e } \\
\text { cosmético }\end{array}$ & falha de comunicação parcial & ocorrência de desvios \\
\hline
\end{tabular}

Tabela 3 - Gravidade dos problemas em cada método.

\begin{tabular}{|c|c|c|c|c|c|c|}
\hline & Pequeno & Médio & Grande & Total & problemas únicos & problemas sobrepostos \\
\hline $\mathrm{AH}$ & 21 & 3 & 3 & 27 & 18 & 9 \\
\hline MAC & 15 & 2 & 3 & 20 & 8 & 12 \\
\hline TU & 2 & 1 & 2 & 5 & 1 & 4 \\
\hline Total & 38 & 6 & 8 & 52 & 27 & 25 \\
\hline
\end{tabular}

Que dificuldades os avaliadores enfrentaram na execução dos métodos? A participação do autor da interface na $\mathrm{AH}$ influenciou sua inspeção. $\mathrm{O}$ autor da interface encontrou uma quantidade menor de problemas, apesar de ter encontrado problemas que outros avaliadores não encontraram. Então, é relevante que o autor da interface participe da avaliação por inspeção do 
seu protótipo, mas também envolva outros avaliadores que não participaram do projeto de IHC.

Em alguns casos, os avaliadores tiveram dificuldades em definir a heurística violada e a gravidade na $\mathrm{AH}$. Esta dificuldade foi análoga à dificuldade de etiquetar os vídeos no MAC. Em ambos os casos, os avaliadores demonstravam dúvidas em classificações (heurísticas, gravidades ou etiquetas) com significados próximos.

AH e MAC orientaram o avaliador a perceber características indesejadas (sintomas) na experiência de uso (possível ou observada) através do emprego de heurísticas e etiquetas. Estes métodos permitem relacionar os sintomas de uma experiência negativa (possível ou real) com características indesejáveis da interface (problema). Com esse diagnóstico, os avaliadores conseguiram sugerir facilmente soluções (modificações) para o projeto de interface sendo concebido. Já no TU, o avaliador não teve dificuldade em identificar os sintomas (desvios, pedidos de ajuda, tempo de execução), mas sentiu muita dificuldade em identificar características da interface que poderiam ter causado tais sintomas. O que pode ter causado um desvio de 3 passos? O que levou o participante a pedir ajuda? Qual é causa de um tempo de execução ineficiente? 0 que deve ser mudado na interface e por quê? É difícil responder perguntas como essas analisando apenas os dados quantitativos num TU. Talvez o TU possa ser mais útil para outros objetivos de avaliação, do que para a identificação de problemas na interface. Por exemplo, TU poderia ser usado para comparar soluções alternativas: “Qual é a solução mais eficiente?" ou "Qual é a solução mais fácil de aprender?".

A documentação dos resultados foi extremamente resumida e sem justificativas em todos os métodos. Essas documentações podem ser úteis para o consumo próprio no curto prazo, mas seria deficiente para terceiros ou para consumo próprio em médio e longo prazo devido ao esquecimento. No MAC, o avaliador desistiu de elaborar o perfil semiótico conforme prescrito pelo método. Ele considerou mais fácil e adequado enumerar uma lista de sintomas, problemas e soluções. Essa lista foi bastante útil para orientar o seu reprojeto, cuja discussão está fora do escopo deste artigo.

O método mais simples e rápido foi a $\mathrm{AH}$. Porém, muitos problemas passam despercebidos sem os caminhos de interação explorados pelos usuários. O ideal é conjugar métodos de inspeção e de observação. Uma combinação promissora seria empregar a AH na avaliação formativa, por ser barato o suficiente para permitir mais de uma execução num processo de design iterativo com base em protótipos; e empregar o MAC na avaliação somativa antes do lançamento do sistema, por considerar os pontos de vista de usuários numa versão quase final do sistema.

\section{Considerações Finais}

Este artigo relatou um estudo de caso das primeiras experiências de avaliação de IHC de profissionais de TI da SoftUrbano, durante o projeto de interface para smartphone do seu sistema jurídico. O autor da interface empregou nesta ordem a avaliação heurística (Nielsen, 1994), o método de avaliação de comunicabilidade (Prates et al., 2000) e o teste de usabilidade (Rubin e Chisnell, 2008) para encontrar problemas na sua solução de interface. A análise destas experiências considerou tempo e materiais, avaliadores e usuários necessários para execução dos métodos, bem como resultados encontrados e dificuldades enfrentadas.

Por não contar com a participação de usuários, a AH foi o método de tempo de execução mais rápido, seguido pelos métodos de observação $\mathrm{MAC}$, depois pelo TU. Eles utilizaram quase os 
mesmos materiais e poderiam dispensar o uso da filmadora para gravar o movimento das mãos dos usuários.

A AH exigiu mais 2 avaliadores do que os métodos de observação. A falta ou pouco conhecimento sobre IHC não impediu que os avaliadores obtivessem resultados relevantes lendo uma literatura básica. Contudo, ainda é preciso investigar o impacto desta lacuna na formação e experiência dos avaliadores nos resultados falsos positivos e falsos negativos.

Nas análises qualitativas da $\mathrm{AH}$ e MAC, os avaliadores perceberam sem dificuldade sintomas indesejados nas experiências de uso previstas ou observadas. Por outro lado, eles manifestaram dificuldades em atribuir significado a estes sintomas quando realizaram classificações (heurísticas, gravidade ou etiquetas) de significados próximos. Isso exigiu releitura das definições dos métodos e uma melhor compreensão da experiência de uso analisada. Maior conhecimento e experiência em IHC poderiam diminuir essas dificuldades de interpretação, mas ainda assim os avaliadores precisariam empenhar esforços para compreender em profundidade os problemas em questão. Já na análise quantitativa do TU, o avaliador não manifestou dificuldades.

Mesmo com um esforço considerável no recrutamento, 3 participantes das avaliações por observação não tinham conhecimento esperado sobre Direito. O avaliador foi capaz de identificar algumas poucas tarefas onde os sintomas observados estavam relacionados com a falta de conhecimento do domínio e não com problemas na interface. Mesmo assim, na grande maioria das tarefas a participação dessas pessoas contribuiu para a identificação de problemas de interface. Com os cuidados necessários na interpretação dos dados, foi relevante a participação de pessoas com pouco conhecimento do domínio na avaliação de IHC.

Os métodos de avaliação deveriam orientar os avaliadores a identificar sintomas (características indesejadas na experiência de uso) causados por problemas (características indesejadas) na interface. Por sua vez, a identificação e compreensão dos problemas de interface orientariam a sugestão de melhorias na solução sendo concebida. Os métodos qualitativos AH e MAC empregados no caso estudado apoiaram os avaliadores na identificação de sintomas, problemas e solução. Já a execução puramente quantitativa do TU realizada neste caso orientou a identificação dos sintomas, mas deixou bastante a desejar na identificação dos problemas e sugestão de soluções. Isso prejudicou muito a quantidade de problemas identificados pelo TU.

Mais de $70 \%$ dos problemas encontrados foram problemas com origem em apenas um dos métodos executados. Foram 18 problemas únicos identificados pela $\mathrm{AH}, 8$ pelo MAC e apenas 1 pelo TU. Apesar de a AH ter sido o método mais rápido, ele não foi capaz de encontrar um bom número de problemas. Deste modo, nenhum dos métodos deveria ser utilizado isoladamente, nem mesmo a $\mathrm{AH}$. O ideal seria conjugar diferentes métodos. Em relação à gravidade, a $\mathrm{AH}$ encontrou o maior número de problemas pequenos. Todavia, não houve diferença significativa na quantidade de problemas médios e graves entre AH e MAC.

Dos 3 avaliadores que participaram da $\mathrm{AH}$, o autor da interface encontrou a menor quantidade de problemas num método de inspeção. Ainda assim, sua participação foi relevante porque ele encontrou problemas que outros avaliadores não encontraram. Não houve indícios de que o autor da interface tenha intimidado os outros avaliadores contra o relato de problemas. Já quando se trata de um método de avaliação por observação, o autor da interface foi capaz de encontrar, sem grandes dificuldades, um número considerável de problemas na sua solução de interface. Ele identificou 8 problemas na $\mathrm{AH}$, contra 20 problemas no MAC (+250\%). Isso ocorreu 
porque na observação de usuários, a análise do avaliador se guia pelo comportamento dos usuários e não pela sua opinião/interpretação sobre a solução (concebida por ele mesmo). Apesar deste caso não ter contado com um profissional formado num curso superior em Design, acreditase que a participação do designer na avaliação formativa apresente resultados semelhantes.

Existem trabalhos que investigam métodos de avaliação de IHC específicos para dispositivos móveis (Betiol e Cybis, 2004; Duh et al., 2006). Estes trabalhos estão preocupados com a mobilidade e seus efeitos na experiência de uso. Contudo, preocupações com a mobilidade não fizeram parte desta pesquisa. O foco foi identificar e resolver problemas de interface sem influencia da mobilidade e contexto.

Outros trabalhos relacionados também comparam métodos de avaliação de IHC (Jeffries et al., 1991; Karat et al., 1992; Salgado et al., 2006). A maioria faz uma análise quantitativa considerando a quantidade absoluta e severidade de problemas encontrados pelos métodos de $\mathrm{AH}$, percurso cognitivo e TU. (Salgado et al., 2006) foi o único trabalho encontrado que compara também o MAC, considerando também aspectos qualitativos. Este é o trabalho relacionado que mais se aproxima do estudo apresentado aqui. Nenhum deles, no entanto, considerou problemas sobrepostos ou equivalentes entre os métodos comparados.

Salgado e suas colegas (2006) afirmam que os métodos de avaliação requerem especialistas em IHC (para a $\mathrm{AH}$ ) e especialistas em engenharia semiótica (para o MAC). Diferente do que elas argumentam, as avaliações apresentadas neste estudo de caso foram realizadas por profissionais de $\mathrm{TI}$ não especialistas em IHC, nem em engenharia semiótica. Eles somente realizaram uma leitura dos métodos antes da execução. Apesar dos falsos positivos e falsos negativos não terem sido analisados, os resultados das avaliações realizadas por estes profissionais contribuíram significativamente para a revisão e melhoria do projeto de interface.

A AH de (Salgado et al., 2006) consumiu $5 \mathrm{~h}$ com dois avaliadores, enquanto que a AH neste estudo durou 5h03min com 3 avaliadores. No MAC, (Salgado et al., 2006) consumiu 13h com a participação de 4 usuários, enquanto neste estudo gastou-se 17h24min com 5 usuários.

Outra diferença fundamental do estudo de (Salgado et al., 2006) para este, é que elas avaliaram um software comercial pronto (RealPlayer), com avaliadores especialistas em IHC que não participaram do projeto do sistema avaliado. Este estudo de caso, por outro lado, analisou a experiência de um autor de interface em avaliações formativas da sua própria solução. Esta é uma perspectiva diferente que destaca significativamente este trabalho dos trabalhos anteriores.

Em resumo, o caso estudado ensinou que é possível e relevante que o autor (designer) realize avaliações formativas da sua própria solução de IHC, com mais de um método, ainda que as condições não sejam as ideais. Com os cuidados necessários, avaliações de IHC em condições não ideais podem trazer contribuições relevantes para identificação de problemas e melhoria da solução sendo concebida.

Em trabalhos futuros seria interessante realizar estudos semelhantes com outros sistemas e profissionais, incluindo aqueles com formação em Design. Também seria interessante comparar métodos tradicionais de avaliação de IHC com os métodos específicos para dispositivos móveis, que consideram a mobilidade, contexto e as particularidades da interface desses dispositivos. É preciso aprofundar a análise dos problemas encontrados, para verificar falsos positivos, falsos negativos e outros aspectos relevantes dessa experiência tão rica. 


\section{Referências}

BARBOSA, S.D.J. e SILVA, B.S. Interação Humano-Computador. Série SBC- Campus. Elsevier, 2010. BETIOL, A.H., CYBIS, W. Avaliação de usabilidade para os computadores de mão: um estudo comparativo entre três abordagens para ensaios de interação. Anais do VI Simpósio Brasileiro sobre Fatores Humanos em Sistemas Computacionais, IHC 2004, p. 19, 2004.

DE SOUZA, C.S. The Semiotic Engineering of Human-Computer Interaction. MIT Press, 2005.

DUH, H. TAN, G., CHEN, V. Usability evaluation for mobile device: A comparison of laboratory and field tests. In Proceedings of the 8th Conference on Human-Computer Interaction With Mobile Devices and Services (MobileHCI), pp. 181-186, 2006.

JEFFRIES, R., MILLER, J.R., WHARTON, C. and UYEDA, K.M. User Interface Evaluation in the real world: a comparison of four techniques. In Proceedings of CHI'91, pp. 119-124, 1991.

KARAT, C.M., CAMPBELL, R., and FIEGEL, T. Comparison of empirical testing and walkthrough methods in user interface evaluation. In Proceedings of CHI'92, pp. 397-404, 1992.

LAWSON, B.R. How Designers Think: The Design Process Demystified, Fourth Edition. Elsevier, 2006.

MARCONI, M.A.; LAKATOS, E.M. Fundamentos de metodologia científica. 7. ed. Atlas, 2010.

NIELSEN, J. Heuristic Evaluation. In: Mack, R.; Nielsen, J. (eds.), Usability Inspection Methods. New York, NY: John Wiley \& Sons, pp. 25-62, 1994.

PRATES, R.O.; DE SOUZA, C.S.; BARBOSA, S.D.J. A method for evaluating the communicability of user interfaces. ACM Interactions 7 (1), pp. 31-38, 2000.

RUBIN, J.; CHISNELL, D. Handbook of Usability Testing: How to Plan, Design, and Conduct Effective Tests, 2a edição. Indianapolis, IN: Wiley Publishing, 2008.

SALGADO, L.C.C.; BIM, S.A.; DE SOUZA, C.S. Comparação entre os métodos de avaliação de base cognitiva e semiótica. Anais do Simpósio sobre Fatores Humanos em Sistemas Computacionais, IHC 2006, pp. 158-167, 2006.

SHARP, H. ROGERS, Y. e PREECE, J. Interaction Design: Beyond Human-computer Interaction. Second Edition. New York, NY: John Wiley \& Sons, 2007.

STAKE, R.E. The Art of Case Study Research. Sage Publications, 1995.

YIN, R.K. Applications of Case Study. SAGE Publications, 2011. 